\title{
Clinical impact review \\ Ivabradine: the evidence of its therapeutic impact in angina
}

\author{
Guillaume Marquis-Gravel, Jean-Claude Tardif \\ Montreal Heart Institute, Université de Montréal, Montreal, Quebec, Canada
}

\begin{abstract}
Introduction: Stable angina pectoris (SAP) is a widely prevalent disease affecting 30000 to 40000 per million people in Europe and the US. SAP is associated with reductions in quality of life and ability to work, and increased use of healthcare resources. Ivabradine is a drug with a unique therapeutic target, the $I_{f}$ current of the sinus node, developed for the treatment of cardiovascular diseases including SAP. It has an exclusive heart rate reducing effect, without any negative effect on left ventricular function or coronary vasodilatation.
\end{abstract}

Aims: The aim of this paper is to review the evidence concerning the use of ivabradine in the treatment of SAP.

Evidence review: Ivabradine is an effective antianginal and antiischemic drug, not inferior to the beta blocker atenolol and the calcium channel antagonist (CCA) amlodipine. It decreases the frequency of angina attacks and increases the time to anginal symptoms during exercise. Because of its exclusive chronotropic effect, ivabradine is not associated with the typical adverse reactions associated with beta blockers or other antianginal drugs.

Clinical value: Clinical evidence shows that ivabradine is a very good antiischemic and antianginal agent, being as effective as beta blockade and CCA therapy in controlling myocardial ischemia and symptoms of stable angina. Ongoing studies will determine the potential of ivabradine to improve morbidity and mortality in coronary artery disease and heart failure.

Core Evidence. 2008;3(1)1:1-12

doi: $10.3355 /$ ce.2008.008

Key words: evidence, $I_{\mathrm{f}}$ current, ivabradine, outcomes, stable angina pectoris, treatment

\section{Core evidence clinical impact summary for ivabradine in angina}

\begin{tabular}{|c|c|c|}
\hline Outcome measure & Evidence & Implications \\
\hline \multicolumn{3}{|l|}{ Patient-oriented evidence } \\
\hline Decrease in angina attack frequency & Clear & Ivabradine reduces the frequency of angina attacks at least as effectively as atenolol and amlodipine \\
\hline $\begin{array}{l}\text { Decrease in short-acting } \\
\text { nitrate consumption }\end{array}$ & Clear & Ivabradine reduces the need for short-acting nitrate consumption as well as atenolol and amlodipine \\
\hline $\begin{array}{l}\text { Increase in time to angina onset and } \\
\text { to limiting angina during exercise }\end{array}$ & Clear & $\begin{array}{l}\text { Ivabradine } 7.5 \mathrm{mg} \text { bid is as effective as atenolol } 100 \mathrm{mg} \text { od and amlodipine } 10 \mathrm{mg} \text { od in increasing time } \\
\text { to angina onset and time to limiting angina during exercise }\end{array}$ \\
\hline Increase in total exercise duration & Clear & $\begin{array}{l}\text { Ivabradine } 7.5 \mathrm{mg} \text { bid is as effective as beta blockade (atenolol } 100 \mathrm{mg} \text { od) and calcium channel } \\
\text { antagonist (amlodipine } 10 \mathrm{mg} \text { once daily) therapy in increasing total exercise duration }\end{array}$ \\
\hline $\begin{array}{l}\text { Absence of rebound effect } \\
\text { after withdrawal }\end{array}$ & Clear & No rebound effect (unlike beta blockers) and no drug tolerance (unlike nitrates) with ivabradine \\
\hline Reduction in mortality & No evidence & The BEAUTIFUL and SHIFT trials are ongoing \\
\hline \multicolumn{3}{|l|}{ Disease-oriented evidence } \\
\hline $\begin{array}{l}\text { Increase in time to } 1 \mathrm{~mm} \mathrm{ST} \text { segment } \\
\text { depression during exercise }\end{array}$ & Clear & $\begin{array}{l}\text { Ivabradine } 7.5 \mathrm{mg} \text { bid is equivalent to atenolol } 100 \mathrm{mg} \text { od and amlodipine } 10 \mathrm{mg} \text { od in increasing time } \\
\text { to } 1 \mathrm{~mm} \text { ST segment depression during exercise tolerance testing }\end{array}$ \\
\hline Decrease in heart rate & Clear & Heart rate at rest and during exercise is significantly reduced with the use of ivabradine \\
\hline $\begin{array}{l}\text { Decrease in heart rate-pressure } \\
\text { product }\end{array}$ & Clear & Ivabradine decreases the rate-pressure product \\
\hline \multicolumn{3}{|l|}{ Economic evidence } \\
\hline $\begin{array}{l}\text { Cost effectiveness in the treatment } \\
\text { of SAP }\end{array}$ & No evidence & Studies required \\
\hline
\end{tabular}




\section{Scope, aims, and objectives}

Stable angina pectoris (SAP) is an ischemic heart disease affecting 30000 to 40000 per million people in Europe and the US (ESC 2006). Besides the burden of a reduced quality of life, patients with SAP have a higher risk of experiencing major cardiovascular events such as myocardial infarction (MI) and unstable angina. Thus, the management of SAP involves secondary prevention as well as symptomatic treatment. It includes therapeutic lifestyle changes, drug therapy, and, to a lesser extent, invasive procedures. The medications currently used for the management of SAP are mainly beta blockers (e.g. atenolol), calcium channel antagonists (CCAs) (e.g. amlodipine), and nitrates. Over the last decade, a new therapeutic target, the $f$ channel in the sinus node, has been evaluated and the $I_{\mathrm{f}}$ current inhibitor ivabradine (Procoralan ${ }^{\circledR}$, Corlentor $^{\circledR}$, Coralan $^{\circledR}$, Coraxan ${ }^{\circledR}$, Servier) was approved for the treatment of SAP by the European Medicines Agency (EMEA) in 2005. This new pharmacologic agent provides a unique mechanism of action involving an exclusive reduction in heart rate (HR), without any inotropic or coronary vasoconstrictive effect.

The aim of this review is to describe the clinical evidence for the role of ivabradine in the treatment of SAP.

\section{Methods}

A search of medical literature was conducted for relevant information about the role of ivabradine in the treatment of angina. The terms "ivabradine" and "angina" were used for the search, and it was limited to English language articles. The databases used were:

- PubMed, http://www.ncbi.nlm.nih.gov/entrez, 1996 to date

- EMBASE, http://www.datastarweb.com, 1974 to date

- BIOSIS, http://www.datastarweb.com

- York University Centre for Reviews and Dissemination databases

- Cochrane Databases of Systematic Reviews (CDSR), http://www.cochrane.org/index.htm (entire site searched).

Articles concerning animal and in-vitro studies were excluded. No systematic reviews or meta analyses were identified in this literature search. Among all the articles found, three articles and one abstract were included in the final evidence base as level 2 clinical evidence records (Table 1).

\section{Disease overview}

SAP is an ischemic heart syndrome typically characterized by brief chest discomfort, lasting usually less than $10 \mathrm{~min}$, triggered by exertion or emotional stress. As a common manifestation of coronary artery disease (CAD), SAP is therefore caused by an imbalance between the oxygen demand
Table 1 | Evidence base included in the review

\begin{tabular}{|lcc|}
\hline Category & \multicolumn{2}{c|}{ Number of records } \\
\cline { 2 - 3 } & Full papers & Abstracts \\
\hline Initial search & 116 & 1 \\
records excluded & 108 & 0 \\
records included & 8 & 1 \\
Additional studies identified & 0 & 0 \\
Level 1 clinical evidence & 0 & 0 \\
Level 2 clinical evidence (RCT) & 3 & 1 \\
Level $\geq 3$ clinical evidence & 0 & 0 \\
trials other than RCT & 0 & 0 \\
case studies & 0 & 0 \\
Economic evidence & 0 & 0 \\
\hline For definitions of levels of evidence, see Editorial Information on inside back cover or on \\
Core Evidence website (http://www.coremedicalpublishing.com). \\
RCT, randomized controlled trial.
\end{tabular}

of the heart and the blood flow to the myocardial cells. It is usually described as a constrictive or burning sensation located near the sternum, but it can radiate to the epigastrium, the neck, the jaw, and the arms, especially the left one. The symptoms of pain associated with SAP can be relieved by rest or by short-acting sublingual nitroglycerin. Dyspnea and palpitations can come along with the pain, or can occur as equivalent SAP symptoms. Chest pain can be classified according to the following characteristics involved in the syndrome: (1) substernal chest discomfort of characteristic quality and duration; (2) provoked by exertion or emotional stress; and (3) relieved by rest and/or nitroglycerin. Typical angina involves all three characteristics and atypical angina involves two of them, while noncardiac chest pain usually involves one or none of them (Diamond 1983). More than half of patients experience anginal symptoms at least once a week (Gandhi et al. 1995).

Multiple diseases have the potential to predispose to angina episodes, including aortic stenosis, left ventricular hypertrophy, hypotension, arrhythmias, and anemia, but the most commonly encountered etiology is coronary stenosis due to atherosclerosis in CAD. Quality of life is reduced with SAP, with the majority of patients perceiving that they have a poor or fair health condition, and this proportion increases with the frequency of the angina episodes (Pepine et al. 1998). This condition affects significantly more women than men overall, but the prevalence is higher in men aged under 70 (Deckers 2005). It is believed that estrogens may play a protective role against atherosclerosis and SAP, and postmenopausal women are affected by CAD two- to three-fold more than premenopausal women (Kannel et al. 1976). In a cohort of patients with SAP observed in the early 1990s, female patients were significantly older than men, and the prevalence of cardiovascular conditions associated with SAP was $70 \%$ (Pepine et al. 1998). The prevalence of SAP increases with age, varying from $2-5 \%$ to $11-20 \%$ in men aged $45-54$ years and 65-74 years, respectively (Tendera 2005). In women, the 
prevalence is $0.5-1.0 \%$ and $10-14 \%$ for the same age groups. In the US, the incidence of SAP is 400000 per year, and 452300 people died because of CAD in 2004, with a higher proportion for males. In the UK, a study has shown that the annual incidence of SAP is 2.03 for men and 1.89 for women per 100 people (AHA 2008).

The grading of SAP used to evaluate its severity comprises four angina classes, according to the Canadian Cardiovascular Society Classification (Table 2). This classification is useful to assess patients' quality of life and to determine their response to therapy. In a study conducted in the mid-1990s, approximately $11 \%$ of the patients diagnosed with de novo SAP experienced nonfatal MI or death within one year of followup (Gandhi et al. 1995). The probability of experiencing an acute coronary syndrome when suffering from SAP increases with the presence of $C A D$ risk factors. The typical $C A D$ risk factors are smoking, hypertension, dyslipidemia, physical inactivity, obesity, and diabetes mellitus (AHA 2008).

\begin{tabular}{|c|c|}
\hline Class & Level of symptoms \\
\hline \multirow[t]{2}{*}{ I } & "Ordinary activity does not cause angina" \\
\hline & Angina with strenuous or rapid or prolonged exertion only \\
\hline \multirow[t]{2}{*}{$\|$} & "Slight limitation of ordinary activity" \\
\hline & $\begin{array}{l}\text { Angina on walking or climbing stairs rapidly, walking uphill, or } \\
\text { exertion after meals, in cold weather, when under emotional } \\
\text { stress, or only during the first few hours after awakening }\end{array}$ \\
\hline \multirow[t]{2}{*}{ III } & "Marked limitation of ordinary physical activity" \\
\hline & $\begin{array}{l}\text { Angina on walking one or two blocks on the level or one flight of } \\
\text { stairs at a normal pace under normal conditions }\end{array}$ \\
\hline IV & $\begin{array}{l}\text { "Inability to carry out any physical activity without discomfort" or } \\
\text { "angina at rest" }\end{array}$ \\
\hline
\end{tabular}

A high HR is an important risk factor for experiencing an episode of angina, given that it shortens the perfusion time of the myocardium by decreasing the duration of diastole, and also because it increases the oxygen demand of the heart. HR is one of the most important determinants of myocardial oxygen demand. Furthermore, an elevated HR at rest is associated with increases in all-cause mortality, cardiovascular mortality, and time to cardiovascular rehospitalization in patients with CAD, independently of major cardiovascular risk factors (Kannel et al. 1987; Mensink et al. 1997; Diaz et al. 2005). It is also independently associated with greater coronary atherosclerosis progression (Perski et al. 1992). The in-hospital HR of patients hospitalized for acute $\mathrm{MI}$ is an independent risk predictor of mortality at one year (Fox et al. 1996). Moreover, a HR over 80 beats per min (bpm) is associated with an increased risk of atherosclerotic plaque rupture (Heidland et al. 2001). In patients suffering from the metabolic syndrome or hypertension, the HR at rest is also associated with increased mortality (Diaz et al. 2005). A recent meta regression analysis has shown that reducing HR may be associated with a decrease in cardiovascular morbidity and mortality (Cucherat 2007).

\section{Current therapeutic options in stable angina pectoris}

The aims of the treatment of SAP are both to prevent Ml and cardiac death and to decrease the frequency and severity of the symptoms in order to improve functional capacity (Gibbons et al. 2002; ESC 2006). Therefore, the goal is to increase both the quantity and the quality of life, with a greater focus on secondary prevention to improve prognosis. The general management of patients with SAP includes therapeutic lifestyle changes targeting risk factors that may have been involved in the development of the disease, pharmacologic intervention, and, if necessary, revascularization. Risk factor management includes smoking cessation, weight control, physical activity, and the medical and lifestyle control of hypercholesterolemia, diabetes mellitus, and hypertension. Drugs recommended for the prevention of major cardiovascular events in CAD patients include antiplatelet agents (particularly aspirin), lipid-lowering agents (particularly statins), and angiotensin-converting enzyme (ACE) inhibitors (Gibbons et al. 2002; ESC 2006). The most effective agents currently available to control anginal and ischemic symptoms are beta blockers, CCAs, and nitrates. These drugs all have the ability, through different mechanisms and to different extents, to decrease the heart's oxygen demand and to increase the perfusion to the myocardium.

Beta blockers are recommended as the initial symptomatic therapy of SAP if there is no contraindication, with a higher level of evidence for patients with prior MI (Gibbons et al. 2002; ESC 2006). A strong positive correlation exists between the reduction in HR with beta blockers and the decrease in mortality among post-MI patients (Singh 2001). Beta blockers decrease the heart's oxygen demand primarily by slowing $\mathrm{HR}$, in addition to reducing blood pressure and myocardial contractility (Guth et al. 1987; Egstrup 1988; Saha \& Marber 2005). These agents are also capable of increasing exercise tolerance and decreasing nitrate consumption. The dose of beta blocker is usually adjusted to a target HR of $50-60 \mathrm{bpm}$ in patients with SAP if there is no contraindication or side effect. No systematic review has been conducted to assess changes in quality of life of patients with SAP treated with beta blockers. Of note, beta blockers must be avoided in patients with vasospastic angina.

The use of CCAs to reduce the symptoms of SAP is recommended if beta blockers are contraindicated. This class of agent can also be prescribed in combination with long-acting nitrates or beta blockers; dihydropyridine CCAs are preferable when used in conjunction with beta blockade (Wallace et al. 1994; Fox et al. 1996; Rehnqvist et al. 1996; Heidenreich et al. 1999; AHA/ACA 2002; ESC 2006). CCAs exert their action by their negative inotropic effect, and their ability to produce peripheral vasodilatation (thus reducing blood pressure) and to decrease coronary vascular resistance. Thus, the antianginal and antiischemic properties of CCAs are mediated by their ability to decrease the heart's oxygen demand and increase coronary flow (Brogden et al. 1996). Long-acting CCAs have generally been as effective as beta blockers in relieving angina symptoms, and improving time to ischemia and time to onset of angina during exercise (Gibbons et al. 2002). 
The antianginal properties of nitrates can be attributed to the augmentation of coronary flow and to the decrease in the heart's oxygen consumption that they cause. Nitrates induce coronary vasodilatation, leading to better myocardial perfusion. They also produce venodilatation, leading to decreased venous return, and thus to reduced cardiac preload. Nitroglycerin also exerts antiplatelet effects in patients with SAP (Lacoste et al. 1994). Short-acting nitroglycerin is used sublingually to relieve symptoms of angina. Long-acting nitrates can be used in combination with a beta blocker if monotherapy has proven unsuccessful, or in combination with CCAs if beta blockade leads to unacceptable adverse drug reactions. During exercise, nitrates increase the delay before the onset of angina and the time to $1 \mathrm{~mm}$ ST segment depression (TST), but their effects are improved when used in combination with another antianginal agent (Akhras et al. 1991). Nitrates should be administered intermittently, with 8 to 12 hours of nitrate-free intervals, to prevent pharmacologic tolerance. However, a rebound phenomenon with anginal symptoms is possible during these intervals.

Other antianginal agents include potassium channel activators, trimetazidine, L-carnitine, ranolazine, and ACE inhibitors, but their clinical efficacy remains to be proven. With the exception of ACE inhibitors in patients with concomitant CAD and diabetes or left ventricular systolic dysfunction (Gibbons et al. 2002; ESC 2006), no guidelines currently recommend the use of these agents in the treatment of SAP.

In summary, for the prevention of anginal symptoms, current guidelines (Gibbons et al. 2002; ESC 2006) recommend beta blockers as the first-line therapy, particularly in post-MI patients, and combination with CCAs or long-acting nitrates can be used if the initial treatment is unsuccessful. If intolerance to beta blockers develops, or in the presence of contraindications, monotherapy with a CCA, an $I_{f}$ inhibitor (where available), a long-acting nitrate, or a potassium channel opener is indicated. These agents can be used in combination if monotherapy is not effective. Surgical or percutaneous revascularization should be reserved for patients whose symptoms are not well controlled by optimal medical therapy, or for those with severe left main coronary artery disease or severe multivessel disease.

\section{Unmet needs}

The main limitations of current pharmacologic therapy for SAP are the contraindications and side effects of the different classes of antianginal agents. Patient compliance with beta blockers can be limited by side effects such as fatigue, sexual dysfunction, bronchospasm, cold extremities, worsening claudication, light headedness, gastrointestinal disturbances, bradycardia, and atrioventricular (AV) block (Tafreshi \& Weinacher 1999; Gibbons et al. 2002; Ko et al. 2002; ESC 2006). In addition, beta blockers can be associated with unfavorable metabolic effects on glycemic control and on the lipid profile, as well as with inhibition of the adrenergic response to hypoglycemia. Contraindications for beta blockers include severe bradycardia, high-degree AV block, sick sinus syndrome, and unstable heart failure (Gibbons et al. 2002). The presence of asthma or chronic obstructive pulmonary disease represents a relative contraindication to beta blockade (Gibbons et al. 2002). A rebound increase in myocardial ischemia, potentially associated with tachycardia, hypertension, MI, and unstable angina, after abrupt withdrawal of beta blocker therapy, makes progressive dosage reduction necessary when withdrawal of beta blockade is needed (Frishman 1987; Egstrup 1988). Many patients are not prescribed beta blockers after MI, despite the strong evidence of benefit when these agents are used for secondary prevention in this setting (Hanania 2004). Despite the availability of beta blockers, resting HR may not be sufficiently controlled to the target of $55-60 \mathrm{bpm}$. In one recent study, patients with CAD had a mean HR of $70 \mathrm{bpm}$ despite use of beta blockers by $61 \%$ of patients (Newby et al. 2006).

Side effects of CCAs include hypotension, lower extremity edema (with dihydropyridine CCAs), and constipation (with verapamil). The contraindications for the use of nondihydropyridine CCAs are bradycardia, AV conduction block, and sinus node dysfunction. CCAs should also not be used in patients with both SAP and left ventricular systolic dysfunction, except for amlodipine, which has been shown to be safe in this setting. Some reports have indicated that immediate-release and short-acting CCAs could increase the risk of cardiovascular mortality in patients with SAP, diabetes and/or hypertension in a dose-related fashion, and these formulations should therefore not be used (Furberg et al. 1995; Estacio et al. 1998).

The most frequent side effect of nitrates is headache, reported by up to $82 \%$ of patients in placebo-controlled trials in a dose-related fashion, with about $10 \%$ of patients reporting severe symptoms leading to discontinuation of the treatment (Thadani \& Rodgers 2006). Hypotension is frequent and usually asymptomatic, although syncope can rarely occur. The tolerance phenomenon associated with the chronic use of long-acting nitrates imposes the need for an 8-12 hour nitrate-free interval every day, which can occasionally lead to angina attacks at night during this period. Nitrates are contraindicated in patients with severe aortic stenosis or hypertrophic obstructive cardiomyopathy. Furthermore, concomitant use of nitrates and sildenafil can provoke severe potentially life-threatening hypotension, making this combination an absolute contraindication. Indeed, patients should be warned never to use sildenafil within 24 hours of nitrate consumption (Cheitlin et al. 1999).

Ivabradine is an inhibitor of the selective cardiac pacemaker hyperpolarized-activated $\mathrm{I}_{f}$ current, one of the most important pacemaker currents in the sinoatrial node (DiFrancesco \& Camm 2004; Zaza \& Rocchetti 2005). Ivabradine has no negative inotropic or hypotensive effects and is therefore a pure HRlowering agent, in contrast to beta blockers. The results of clinical trials with ivabradine are described below. According to the European Society of Cardiology guidelines (ESC 2006), ivabradine is recommended in patients with SAP who do not tolerate beta blockers. The pure HR-reducing effect of ivabradine offers the advantage of not disturbing hemodynamic parameters or left ventricular systolic and diastolic functions (Manz et al. 2003). Unlike beta blockers, ivabradine does not decrease the diameter of epicardial coronary arteries at rest and the 
augmentation during exercise (Simon et al. 1995). Moreover, the increase in the duration of diastole is greater with ivabradine than with atenolol for a given HR (Colin et al. 2003), a beneficial phenomenon considering that most of the coronary perfusion occurs during diastole.

\section{Clinical evidence with ivabradine}

In this review, it is shown that there is clear evidence that ivabradine is efficacious in reducing HR and decreasing angina attack frequency and short-acting nitrate consumption. The antiischemic and antianginal effects of ivabradine are comparable to those of widely prescribed therapeutic agents from other classes used in SAP.

A phase III clinical trial has been conducted to evaluate the clinical impact of ivabradine in the treatment of SAP, and phase IV studies are ongoing because the European approval for the marketing of ivabradine is relatively recent (2005). The present review focuses on three randomized controlled trials involving ivabradine monotherapy for patients with SAP (Borer et al. 2003; Tardif et al. 2005; Ruzyllo et al. 2007), plus a subgroup analysis from one of these studies (Tendera et al. 2006). No systematic review or meta analysis is included in this review.

\section{Antianginal effects}

\section{Time to angina during exercise (Table 3)}

In the first randomized clinical trial ( $n=360$ patients) testing the antianginal effects of ivabradine (Borer et al. 2003), the time to angina onset and to limiting angina during exercise tolerance test at trough of drug activity (12 hours after drug administration) increased significantly in patients who received ivabradine $10 \mathrm{mg}$ twice daily for two weeks $(n=66)$ compared with placebo $(n=68)$. The mean time to angina onset increased by $69.4 \pm 74.8 \mathrm{~s}$ in the ivabradine group, while it increased by $24.7 \pm 64.2 \mathrm{~s}$ in the placebo group $(P<0.05)$. Mean time to limiting angina, which was the primary efficacy endpoint of the study, increased by $40.8 \pm 69.3 \mathrm{~s}$ and $12.7 \pm 51.3 \mathrm{~s}$, respectively $(P<0.05)$. A similar trend was observed in patients receiving ivabradine $5 \mathrm{mg}$ twice daily $(n=59)$, but it did not reach significance. At peak plasma concentration (4 hours after drug administration), the effects were greater, also reaching significance in the group receiving ivabradine $5 \mathrm{mg}$ twice daily.

After the double-blind phase of the trial, patients entered an open-label phase during which they received ivabradine $10 \mathrm{mg}$ twice daily for 2 or 3 months, followed by a double-blind withdrawal period in which patients were randomized to placebo or to ivabradine $10 \mathrm{mg}$ twice daily. During the open-label phase, time to limiting angina was maintained in patients assigned to ivabradine in the first part of the trial, and it increased in patients who had initially received placebo during the first phase. During the withdrawal phase, time to limiting angina and time to angina onset were significantly longer $(P=0.018$ and $P=0.002$, respectively) in patients who were assigned to remain on ivabradine compared with those receiving placebo.
In 2005, the INITIATIVE investigators published the results of a randomized controlled trial involving 939 patients with SAP (Tardif et al. 2005) in which the noninferiority of ivabradine relative to the beta blocker atenolol was assessed. Study patients were randomized into three groups and therapy was administered for a period of 16 weeks: (1) ivabradine $5 \mathrm{mg}$ twice daily for 4 weeks followed by ivabradine $7.5 \mathrm{mg}$ twice daily for 12 weeks; (2) ivabradine $5 \mathrm{mg}$ twice daily for 4 weeks followed by ivabradine $10 \mathrm{mg}$ twice daily for 12 weeks; or (3) atenolol $50 \mathrm{mg}$ once daily for 4 weeks followed by atenolol $100 \mathrm{mg}$ once daily for 12 weeks. At 16 weeks, patients who were assigned ivabradine $7.5 \mathrm{mg}$ twice daily and $10 \mathrm{mg}$ twice daily had a mean increase of time to limiting angina of $91.8 \pm 131.1 \mathrm{~s}$ and $96.9 \pm 121.1 \mathrm{~s}$, respectively, at trough drug concentrations, versus $85.4 \pm 133.7 \mathrm{~s}$ for atenolol $100 \mathrm{mg}$ once daily $(P<0.001$ for noninferiority of ivabradine). The efficacy of ivabradine relative to atenolol was also established for time to angina onset $(P<0.001$ for noninferiority). During the first 4 weeks of the trial, when the doses were lower, the noninferiority of ivabradine was also established at trough and at peak of drug activity for time to limiting angina and time to angina onset $(P<0.001$ for noninferiority).

The efficacy of ivabradine $7.5 \mathrm{mg}$ twice daily and $10 \mathrm{mg}$ twice daily versus the long-acting CCA amlodipine $10 \mathrm{mg}$ once daily for time to angina onset was also established $(P<0.001$ for noninferiority) at trough of drug activity in patients with SAP in a 3-month randomized, double-blind trial (Ruzyllo et al. 2007). The increases in time to angina onset were $64.7 \pm 104.9,59.7 \pm 110.8$, and $66.6 \pm 99.1 \mathrm{~s}(P<0.05)$, respectively, and the maximal improvement was reached by the end of the first month of therapy.

\section{Total exercise duration (Table 3)}

The noninferiority of ivabradine for total exercise duration during exercise tolerance testing was established relative to atenolol (Tardif et al. 2005) and amlodipine (Ruzyllo et al. 2007) as the primary efficacy endpoint of these trials. In the latter trial, over a 3-month period, ivabradine $7.5 \mathrm{mg}$ twice daily and $10 \mathrm{mg}$ twice daily produced improvements of $27.6 \pm 91.7 \mathrm{~s}$ and $21.7 \pm 94.5 \mathrm{~s}$, respectively, in total exercise duration on a bicycle at trough of drug activity, while amlodipine $10 \mathrm{mg}$ once daily produced an increase of $31.2 \pm 92.0 \mathrm{~s}$. The noninferiority of ivabradine versus amlodipine was significant for both dosages $(P<0.001)$.

In the INITIATIVE noninferiority trial comparing ivabradine with atenolol (Tardif et al. 2005), total exercise duration during treadmill exercise tolerance tests performed according to a modified Bruce protocol at trough drug activity increased by $86.8 \pm 129.0 \mathrm{~s}$ with ivabradine $7.5 \mathrm{mg}$ twice daily, $91.7 \pm 118.8 \mathrm{~s}$ with ivabradine $10 \mathrm{mg}$ twice daily, and $78.8 \pm 133.4 \mathrm{~s}$ with atenolol $100 \mathrm{mg}$ once daily after 16 weeks compared with baseline $(P<0.001$ for noninferiority of ivabradine versus atenolol). Noninferiority of ivabradine was also shown at peak drug activity after 4 weeks and 16 weeks of treatment, and at trough drug activity after 4 weeks. Interestingly, elderly patients randomized in the INITIATIVE trial showed a tendency to greater effectiveness of ivabradine relative to the overall study population, in contrast to atenolol (Tendera et al. 2006). 
Table 3 | Antianginal effects of ivabradine in pateints with SAP

Level of Reference Design and patients Treatment regimen

evidence

evidence

$\begin{array}{lll}\text { Borer et al. } & \text { RCT (superiority trial), } & \text { IVA 2.5-10 mg bid vs } \\ 2003 & 360 \text { patients with } & \text { PLA for 2 wk; then open- } \\ & \text { chronic stable angina } & \text { label phase with IVA } \\ & \text { and documented } & 10 \mathrm{mg} \text { bid for all patients } \\ & \text { coronary } & \text { for } 3 \text { months; then IVA } 10 \\ & \text { heart disease } & \text { mg bid vs PLA for } \\ & & 1 \mathrm{wk}\end{array}$

$1 \mathrm{wk}$

Outcomes

Time to angina during exercise Total exercise duration

TAO and TLA increased at all doses in the Not evaluated

first phase of the trial, but reached

significance only for IVA $10 \mathrm{mg}$ bid at

trough of drug activity, and for IVA 5 and

$10 \mathrm{mg}$ bid at peak of drug activity

In the open-label extension, the increase

in TLA with IVA was significant vs PLA

$(P<0.001)$

During the third phase of the trial, TLA

and TAO were significantly higher with

IVA than with PLA $(P=0.018$ and $P=0.002$, respectively)

Tardif et al. RCT (noninferiority trial), IVA $5 \mathrm{mg}$ bid vs ATE 2005939 patients with SAP $50 \mathrm{mg}$ od for $4 \mathrm{wk}$; then and CAD IVA $7.5 \mathrm{mg}$ bid or $10 \mathrm{mg}$

2

Ruzyllo et al. RCT (noninferiority trial) $2007 \quad$ including 1195 patients with chronic stable angina and documented CAD bid vs ATE $100 \mathrm{mg}$ od for $12 \mathrm{wk}$

TAO increased by $145.2 \pm 153.4 \mathrm{~s}$ and $139.6 \pm 140.6 \mathrm{~s}$ for IVA 7.5 and $10 \mathrm{mg}$ bid, respectively vs $135.2 \pm 154.7 \mathrm{~s}$ for ATE ( $P<0.001$ for noninferiority) at trough of drug activity after $16 \mathrm{wk}$

Noninferiority also shown after 4 wk $(P<0.001)$

For the same time periods, TLA increased by $91.8 \pm 131.1 \mathrm{~s}, 96.9 \pm$ $121.1 \mathrm{~s}$, and $85.4 \pm 133.7 \mathrm{~s}$ for the same groups $(P<0.001$ for noninferiority)

At peak of drug activity, noninferiority for TLA and TAO shown after $4 \mathrm{wk}$ and 16 wk for IVA vs ATE

Noninferiority for TLA was also established at $4 \mathrm{wk}$ and at $16 \mathrm{wk}$ at both trough of drug activity and peak of drug activity for IVA vs ATE

IVA 7.5 or $10 \mathrm{mg}$ bid vs AML $10 \mathrm{mg}$ od for 3 months

TAO increased by $64.7 \pm 104.9 \mathrm{~s}, 59.7$ $\pm 110.8 \mathrm{~s}$, and $66.6 \pm 99.1 \mathrm{~s}$ for IVA $7.5 \mathrm{mg}$ bid, $10 \mathrm{mg}$ bid, and AML $10 \mathrm{mg}$ od, respectively $(P<0.001$ for noninferiority) at trough of drug activity
Increase of $86.8 \pm 129.0 \mathrm{~s}$ and $91.7 \pm 118.8 \mathrm{~s}$ for IVA 7.5 and $10 \mathrm{mg}$ bid, respectively vs $78.8 \pm 133.4 \mathrm{~s}$ for ATE $(P<0.001$ for noninferiority) at trough of drug activity after 16 wk

Noninferiority also shown after $4 \mathrm{wk}$, with $P<0.001$

At peak of drug activity, noninferiority shown after 4 wk and 16 wk for IVA vs ATE

Increase of $27.6 \pm 91.7 \mathrm{~s}, 21.7 \pm 94.5 \mathrm{~s}$, and $31.2 \pm 92.0 \mathrm{~s}$ for IVA $7.5 \mathrm{mg}$ bid, $10 \mathrm{mg}$ bid, and AML $10 \mathrm{mg}$ od, respectively $(P<0.001$ for noninferiority) at trough of drug activity

AML, amlopidine; ATE, atenolol; bid, twice a day; CAD, coronary artery disease; IVA, ivabradine; od, once daily; PLA, placebo; RCT, randomized controlled trial; SAP, stable angina pectoris; TAO, time to angina onset; TLA, time to limiting angina; wk, week.

\section{Angina attack frequency (Table 4)}

In a randomized, placebo-controlled trial (Borer et al. 2003), the frequency of angina attacks was assessed at the end of an openlabel phase during which 161 patients with chronic SAP were assigned to a regimen of ivabradine $10 \mathrm{mg}$ twice daily for 3 months, following a 2-week period during which they received one of the four following regimens in a double-blind fashion: ivabradine $2.5 \mathrm{mg}$ twice daily, ivabradine $5 \mathrm{mg}$ twice daily, ivabradine $10 \mathrm{mg}$ twice daily, or placebo. At the end of this 3-month period, the number of angina attacks per week, as recorded in patients' diaries, was found to be significantly lower than at baseline, decreasing from $4.14 \pm 5.58$ attacks per week to $0.95 \pm 2.24$ attacks per week $(P<0.001)$ (Table 4$)$. The consumption of short-acting nitrates decreased from $2.28 \pm 3.74 \mathrm{U} /$ week to $0.50 \pm 1.14 \mathrm{U} /$ week $(P<0.001)$ during the same period. In a subsequent 1-week withdrawal period following the 3-month open-label phase, angina attack frequency increased by
$0.74 \pm 1.95$ attacks per week for patients assigned to placebo $(P=0.067)$.

The number of angina attacks per week and short-acting nitrate consumption decreased in all groups of patients in the INITIATIVE trial after 4 and 16 weeks, with no significant difference observed between the ivabradine and atenolol groups (Tardif et al. 2005) (Table 4). Angina attacks were reduced by at least $70 \%$ and short-acting nitrate consumption by approximately $66 \%$ in all study groups at 16 weeks. It has also been shown that there are no significant differences in the reduction of the number of angina attacks and short-acting nitrate consumption between ivabradine $7.5 \mathrm{mg}$ twice daily and $10 \mathrm{mg}$ twice daily versus amlodipine $10 \mathrm{mg}$ once daily (Ruzyllo et al. 2007). These two parameters decreased significantly by approximately $60 \%$ and $50-60 \%$, respectively, with ivabradine and amlodipine $(P<0.001)$. 


\section{Antiischemic effects (Table 5)}

\section{Time to $1 \mathrm{~mm}$ ST segment depression during exercise (Table 5)}

An increase in the TST during exercise tolerance test at trough drug activity was observed in patients treated with ivabradine over a period of 2 weeks in a placebo-controlled trial (Borer et al. 2003). This was the primary efficacy endpoint of that study. The improvement was dose-dependent, being $32.0 \pm 74.3 \mathrm{~s}$, $44.1 \pm 80.1 \mathrm{~s}$, and $46.2 \pm 78.2 \mathrm{~s}$ for ivabradine $2.5 \mathrm{mg}$ twice daily, $5 \mathrm{mg}$ twice daily, and $10 \mathrm{mg}$ twice daily, respectively, at trough drug activity. The difference versus placebo was significant both for the ivabradine $5 \mathrm{mg}$ twice daily and $10 \mathrm{mg}$ twice daily groups. Benefits were also observed when the exercise tolerance test was performed at peak drug activity. During the randomized withdrawal phase, the ivabradine groups also had significantly higher TST than placebo.

In the INITIATIVE study (Tardif et al. 2005), the noninferiority of ivabradine at dosages of $7.5 \mathrm{mg}$ twice daily and $10 \mathrm{mg}$ twice daily was demonstrated versus atenolol $100 \mathrm{mg}$ once daily at trough drug activity for TST during treadmill exercise tolerance test after 16 weeks. After the first 4 weeks of treatment, the efficacy of ivabradine at trough versus atenolol was also

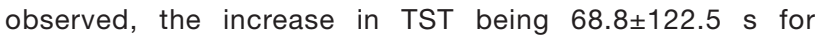
ivabradine $5 \mathrm{mg}$ twice daily and $67.2 \pm 132.3 \mathrm{~s}$ for atenolol $50 \mathrm{mg}$ once daily $(P<0.001$ for noninferiority). TST was evaluated in a subpopulation of the INITIATIVE trial composed of patients aged $\geq 65$ years (Tendera et al. 2006), and the efficacy of ivabradine $7.5 \mathrm{mg}$ twice daily was maintained compared with the overall population of the trial.

In the double-blind trial comparing ivabradine $7.5 \mathrm{mg}$ twice daily and $10 \mathrm{mg}$ twice daily with amlodipine $10 \mathrm{mg}$ once daily, the efficacy of ivabradine for TST during exercise was demonstrated $(P<0.001$ for noninferiority) after a 3-month treatment period (Ruzyllo et al. 2007). The increases in TST were $44.9 \pm 98.6$ s, $34.7 \pm 104.5$ s, and $39.7 \pm 103.2$ s, respectively, in the three study groups.

\section{Decrease of heart rate and rate-pressure product}

The HR at rest and at peak exercise in an exercise tolerance test were both significantly decreased relative to placebo $(P<0.05)$ in the patients who were randomly assigned to one of the three ivabradine groups $(2.5,5$, or $10 \mathrm{mg}$ twice daily) for 2 weeks in a placebocontrolled double-blind trial (Borer et al. 2003). The reduction was dose-dependent and was observed at both peak and trough drug activity. During the randomized withdrawal phase, the mean resting $\mathrm{HR}$ of patients remaining on ivabradine $10 \mathrm{mg}$ twice daily decreased by $0.44 \pm 5.6 \mathrm{bpm}$, compared with a mean increase of $13.3 \pm 8.8 \mathrm{bpm}$ in patients switching to placebo $(P<0.001)$.

In the same trial, the rate-pressure product (RPP) at peak exercise decreased in the three ivabradine groups at trough drug activity,

\section{Table 4 | Effects of ivabradine on angina attack frequency and short-acting nitrate consumption in patients with SAP}

\begin{tabular}{|c|c|c|c|c|c|}
\hline \multirow{2}{*}{$\begin{array}{l}\text { Level of } \\
\text { evidence }\end{array}$} & \multirow[t]{2}{*}{ Reference } & \multirow[t]{2}{*}{ Design and patients } & \multirow[t]{2}{*}{ Treatment regimen } & \multicolumn{2}{|c|}{ Outcomes } \\
\hline & & & & $\begin{array}{l}\text { Frequency of angina attack } \\
\text { (per week) }\end{array}$ & $\begin{array}{l}\text { Short-acting nitrate } \\
\text { consumption (U/wk) }\end{array}$ \\
\hline \multirow[t]{2}{*}{2} & $\begin{array}{l}\text { Borer et al. } \\
2003\end{array}$ & $\begin{array}{l}\text { RCT (superiority trial), } \\
360 \text { patients with chronic } \\
\text { stable angina and } \\
\text { documented coronary } \\
\text { heart disease }\end{array}$ & $\begin{array}{l}\text { IVA } 2.5-10 \mathrm{mg} \text { bid vs PLA for } \\
2 \mathrm{wk} \text {; then open-label phase } \\
\text { with IVA } 10 \mathrm{mg} \text { bid for all } \\
\text { patients for } 3 \text { months; then IVA } \\
10 \mathrm{mg} \text { bid vs PLA for } 1 \mathrm{wk}\end{array}$ & $\begin{array}{l}\text { Nonsignificant reduction with IVA } \\
\text { at all doses during first phase } \\
\text { Decrease from } 4.14 \pm 5.59 \text { at } \\
\text { baseline to } 0.95 \pm 2.24 \text { at the end } \\
\text { of the open-label phase } \\
(P<0.001 \text { vs baseline) }\end{array}$ & $\begin{array}{l}\text { Nonsignificant reduction with IVA } \\
\text { at all doses during first phase } \\
\text { Decrease from } 2.28 \pm 3.74 \text { at } \\
\text { baseline to } 0.50 \pm 1.14 \text { at the end } \\
\text { of the open-label phase }(P<0.001 \\
\text { versus baseline) }\end{array}$ \\
\hline & & & & $\begin{array}{l}\text { Increase by } 0.74 \pm 1.95 \text { in } \\
\text { patients withdrawn to PLA } \\
(P=0.067)\end{array}$ & \\
\hline 2 & $\begin{array}{l}\text { Tardif et al. } \\
2005\end{array}$ & $\begin{array}{l}\text { RCT (noninferiority trial), } \\
939 \text { patients with SAP } \\
\text { and CAD }\end{array}$ & $\begin{array}{l}\text { IVA } 5 \mathrm{mg} \text { bid vs ATE } 50 \mathrm{mg} \text { od } \\
\text { for } 4 \mathrm{wk} \text {; then IVA } 7.5 \mathrm{mg} \text { bid or } \\
10 \mathrm{mg} \text { bid vs ATE } 100 \mathrm{mg} \text { od } \\
\text { for } 12 \mathrm{wk}\end{array}$ & $\begin{array}{l}\text { After } 16 \mathrm{wk} \text {, decrease by } \\
2.2 \pm 4.3,2.3 \pm 4.2 \text {, and } 2.7 \pm 12.3 \\
\text { attacks per week for IVA } 7.5 \mathrm{mg} \\
\text { bid, IVA } 10 \mathrm{mg} \text { bid, and ATE } 100 \\
\mathrm{mg} \text { od, respectively }\end{array}$ & $\begin{array}{l}\text { After } 16 \text { wk, decrease by } 1.6 \pm 4.1 \text {, } \\
1.4 \pm 4.7 \text {, and } 1.2 \pm 3.4 \text { for IVA } 7.5 \\
\mathrm{mg} \text { bid, IVA } 10 \mathrm{mg} \text { bid, and ATE } \\
100 \mathrm{mg} \text { od, respectively }\end{array}$ \\
\hline \multirow[t]{2}{*}{2} & $\begin{array}{l}\text { Ruzyllo et al. } \\
2007\end{array}$ & $\begin{array}{l}\text { RCT (noninferiority trial) } \\
\text { including } 1195 \text { patients with } \\
\text { chronic stable angina and } \\
\text { documented CAD }\end{array}$ & $\begin{array}{l}\text { IVA } 7.5 \text { or } 10 \mathrm{mg} \text { bid vs AML } \\
10 \mathrm{mg} \text { od for } 3 \text { months }\end{array}$ & $\begin{array}{l}\text { Decrease of } 3.0 \pm 5.0 \text { for IVA } \\
7.5 \mathrm{mg} \text { bid and } 3.2 \pm 6.3 \text { for IVA } \\
10 \mathrm{mg} \text { bid vs } 3.0 \pm 6.0 \text { for AML } \\
10 \mathrm{mg} \text { od }(P<0.001 \text { vs baseline } \\
\text { for the three arms) }\end{array}$ & $\begin{array}{l}\text { Decrease of } 1.9 \pm 4.5 \text { for IVA } \\
7.5 \mathrm{mg} \text { bid and } 2.7 \pm 6.3 \text { for IVA } 10 \\
\mathrm{mg} \text { bid vs } 2.7 \pm 6.3 \text { for AML } \\
10 \mathrm{mg} \text { od }(P<0.001 \text { vs baseline } \\
\text { for the three arms) }\end{array}$ \\
\hline & & & & $\begin{array}{l}\text { No significant difference } \\
\text { between IVA and AML }\end{array}$ & $\begin{array}{l}\text { No significant difference between } \\
\text { IVA and AML }\end{array}$ \\
\hline
\end{tabular}

AML, amlopidine; ATE, atenolol; bid, twice a day; CAD, coronary artery disease; IVA, ivabradine; od, once daily; PLA, placebo; RCT, randomized controlled trial; SAP, stable angina pectoris; $\mathrm{U} / \mathrm{wk}$, units per week; wk, week. 


\begin{tabular}{|c|c|c|c|}
\hline $\begin{array}{l}\text { Level of } \\
\text { evidence }\end{array}$ & Reference & Design and patients & Treatment regimen \\
\hline 2 & $\begin{array}{l}\text { Borer et al. } \\
2003\end{array}$ & $\begin{array}{l}\text { RCT (superiority trial), } \\
360 \text { patients with chronic } \\
\text { stable angina and } \\
\text { documented coronary } \\
\text { heart disease }\end{array}$ & $\begin{array}{l}\text { IVA } 2.5-10 \text { mg bid vs PLA for } \\
2 \text { wk; then open-label phase with } \\
\text { IVA } 10 \text { mg bid for all patients for } \\
3 \text { months; then IVA } 10 \text { mg bid vs } \\
\text { PLA for } 1 \text { wk }\end{array}$ \\
\hline
\end{tabular}

$2 \quad$ Tardif et al. 2005 RCT (noninferiority trial), and CAD
IVA $5 \mathrm{mg}$ bid vs ATE $50 \mathrm{mg}$ od for $4 \mathrm{wk}$; then IVA $7.5 \mathrm{mg}$ bid or $10 \mathrm{mg}$ bid vs ATE $100 \mathrm{mg}$ od for $12 \mathrm{wk}$

IVA 7.5 or $10 \mathrm{mg}$ bid vs AML $10 \mathrm{mg}$ od for 3 months

\section{TST}

TST after the first phase of the trial increased by $32.0 \pm 74.3$ $44.1 \pm 80.1$, and $46.2 \pm 78.2 \mathrm{~s}$ for IVA $2.5,5$, and $10 \mathrm{mg}$ bid, respectively vs $9.0 \pm 63.6 \mathrm{~s}$ for PLA at trough of drug activity. Significance was reached for IVA $5 \mathrm{mg}$ bid and $10 \mathrm{mg}$ bid vs PLA $(P<0.05)$

At peak of drug activity, the results were larger and significance was reached for IVA $5 \mathrm{mg}$ bid and $10 \mathrm{mg}$ bid vs PLA $(P<0.05)$

During the third phase, TST increased by $4.25 \pm 59.7 \mathrm{~s}$ for IVA vs decrease of $32.0 \pm 73.7 \mathrm{~s}$ for PLA $(P=0.003)$

After 16 wk, TST was increased by $98.0 \pm 153.7(P<0.001$ for noninferiority) and $86.9 \pm 128.2 \mathrm{~s}(P=0.002$ for noninferiority) for IVA 7.5 and $10 \mathrm{mg}$ bid, respectively vs $95.6 \pm 147.5 \mathrm{~s}$ for ATE at trough of drug activity

After 4 wk, TST was increased by $68.8 \pm 122.5 \mathrm{~s}$ for IVA $5 \mathrm{mg}$ bid vs $67.2 \pm 132.3 \mathrm{~s}$ for ATE $50 \mathrm{mg}$ od at trough of drug activity $(P<0.001$ for noninferiority). At peak of drug activity, noninferiority of IVA vs ATE was shown

TST depression after exercise increased by $44.9 \pm 98.6$ and $34.7 \pm 104.5 \mathrm{~s}$ for IVA 7.5 and $10 \mathrm{mg}$ bid, respectively vs $39.7 \pm 103.2 \mathrm{~s}$ for $\mathrm{AML}$ at trough of drug activity $(P<0.001$ for noninferiority)

\section{Ruzyllo et al. RCT (noninferiority trial) including 1195 patients with chronic stable angina and documented CAD}

AML, amlopidine; ATE, atenolol; bid, twice a day; CAD, coronary artery disease; IVA, ivabradine; od, once daily; PLA, placebo; RCT, randomized controlled trial; s, second; SAP, stable angina pectoris; TST, time to $1 \mathrm{~mm}$ ST segment depression; wk, week.

being significant for the $5 \mathrm{mg}$ twice daily $(-1142 \pm 3354 \mathrm{bpm} / \mathrm{mm} \mathrm{Hg})$ and $10 \mathrm{mg}$ twice daily $(-1543 \pm 3526 \mathrm{bpm} / \mathrm{mm} \mathrm{Hg})$ groups compared with the placebo group $(+266 \pm 3074 \mathrm{bpm} / \mathrm{mm} \mathrm{Hg})$. At peak drug activity, RPP at rest and at peak exercise were significantly lower for the three ivabradine groups compared with placebo $(P<0.001)$. During the randomized withdrawal phase, RPP at trough drug activity increased significantly for patients assigned to placebo, both at rest and during exercise $(P<0.001)$.

In the INITIATIVE trial, comparing ivabradine with atenolol (Tardif et al. 2005), HR and RPP at trough drug activity were reduced in all groups both at rest and during exercise after 4 and 16 weeks. $\mathrm{HR}$ at rest was reduced by $14.3 \pm 11.9,14.3 \pm 13.3$, and $15.6 \pm 12.0 \mathrm{bpm}$ at 16 weeks in the ivabradine $7.5 \mathrm{mg}$ twice daily, ivabradine $10 \mathrm{mg}$ twice daily, and atenolol $100 \mathrm{mg}$ once daily groups, respectively, and by $10.3 \pm 11.1$ and $12.8 \pm 11.4 \mathrm{bpm}$ at 4 weeks in the ivabradine $5 \mathrm{mg}$ twice daily and atenolol $50 \mathrm{mg}$ once daily groups. At peak exercise, HR was reduced by $8.6 \pm 13.7,10.3 \pm 14.1$, and $14.0 \pm 14.4 \mathrm{bpm}$ at 16 weeks in the ivabradine $7.5 \mathrm{mg}$ twice daily, ivabradine $10 \mathrm{mg}$ twice daily, and atenolol $100 \mathrm{mg}$ once daily groups, respectively, and by $7.5 \pm 12.7$ and $11.1 \pm 12.8 \mathrm{bpm}$ at 4 weeks in the ivabradine $5 \mathrm{mg}$ twice daily and atenolol $50 \mathrm{mg}$ once daily groups. Overall ivabradine induced a similar improvement in exercise capacity than atenolol for a comparatively smaller reduction in RPP and HR.

Both HR and RPP were significantly decreased $(P<0.001$ versus baseline) in the ivabradine groups at rest and at peak exercise in the trial comparing ivabradine with amlodipine (Ruzyllo et al. 2007). The maximal reductions in HR and in RPP were reached after 1 month, and remained stable for the following 2 months. As expected, the decrease in HR was minimal and not significant with amlodipine, while the decrease in RPP was significant but still significantly lower than for the ivabradine groups $(P<0.001)$.

\section{Safety}

Visual symptoms and sinus bradycardia are the main adverse reactions observed with the use of ivabradine (Borer et al. 2003; Tardif et al. 2005; Ruzyllo et al. 2007). The visual symptoms are mainly phosphenes, which are episodes of enhanced brightness in limited areas of the visual field frequently triggered by abrupt changes in light intensity. They include photopsia, stroboscopic effect, and nontypical blurred vision, among others. However, the symptoms are generally transient, mild, and do not affect daily living activities. The visual symptoms are probably caused by the interaction of ivabradine with retinal hyperpolarization-activated $h$ channels, responsible for responses to bright light stimuli, which are similar to the $f$ ion channel located in the sinoatrial node (Demontis et al. 2002; Savelieva \& Camm 2006).

In the INITIATIVE trial, visual symptoms were reported by $16.3 \%$ of patients receiving ivabradine $7.5 \mathrm{mg}$ twice daily and $5.6 \%$ of those in the atenolol $100 \mathrm{mg}$ once daily group (Tardif et al. 2005). Similarly, in another study, visual symptoms were reported by $13.0 \%$ of patients in the ivabradine $7.5 \mathrm{mg}$ twice daily group compared with $4.5 \%$ of patients receiving amlodipine $10 \mathrm{mg}$ once daily (Ruzyllo et al. 2007). The visual symptoms resolved spontaneously during or after drug discontinuation, and led to withdrawal in $\leq 1 \%$ of patients, compared with $1.5 \%$ of patients 
withdrawing due to edema related to amlodipine. In a placebocontrolled trial, visual symptoms were reported by $14.8 \%$ of patients receiving ivabradine $10 \mathrm{mg}$ twice daily during the doubleblind phase, versus $0 \%$ in the placebo group (Borer et al. 2003). During the open-label phase, when all patients were assigned to the ivabradine $10 \mathrm{mg}$ twice daily regimen, visual symptoms were reported by $17.9 \%$ of patients. Three patients voluntarily withdrew from the trial because of these symptoms. However, it should be noted that the dosage of ivabradine used in that trial $(10 \mathrm{mg}$ twice daily) is not used clinically.

Sinus bradycardia has been reported by $4.6 \%$ of patients treated with ivabradine $7.5 \mathrm{mg}$ twice daily (Tardif et al. 2005; Ruzyllo et al. 2007). Severe bradycardia (defined as an HR less than $40 \mathrm{bpm}$ ) has been shown to occur in $0.1 \%$ of patients. The QTc interval was not increased in ivabradine recipients compared with atenolol.

The rebound phenomenon described above can occur upon sudden withdrawal of beta blockers (Frishman 1987; Egstrup 1988), but it has not been reported with ivabradine at the dosages used. Also, no pharmacologic tolerance to ivabradine has been reported. Given that ivabradine does not cross the blood-brain barrier, it has no effect on the central nervous system (Savelieva \& Camm 2006). A tolerability profile similar to that in the overall population was observed in an elderly subpopulation with documented CAD (Tendera et al. 2006). The large clinical development program involving 5000 patients with SAP showed that ivabradine has a good tolerability profile with minimal adverse effects that have little impact on patient acceptability.

In summary, clinical evidence shows that ivabradine is a very good antiischemic agent, being at least as effective as beta blockade and CCA therapy in controlling anginal symptoms, with an acceptable tolerability and safety profile.

\section{Economic evidence and resource utilization}

To our knowledge, a cost-effectiveness study has yet to be conducted to evaluate the economic impact of ivabradine in patients with SAP. In the US, the direct and indirect costs of CAD have been estimated to be $\$$ US156.4 billion in 2008 (AHA 2008). In 2005, 469000 coronary artery bypass graft (CABG) procedures and 1265000 percutaneous coronary interventions $(\mathrm{PCl})$ were performed (AHA 2008). Treatment with ivabradine could decrease the need for invasive revascularization and its associated cost. In a study including 883 women with CAD, the estimated lifetime cost of drug treatment and hospitalization was \$US767288 for nonobstructive CAD and \$US1 051302 for two-vessel CAD, with 25.5-32.6\% of these costs attributable to drugs (Shaw et al. 2006). Thus, drug therapy accounts for a significant cost component in patients with CAD.

It has, however, been shown that $\mathrm{PCl}$ is likely to be less cost effective than drug therapy in terms of quality-adjusted lifeyears when this was assessed in a prospective observational study involving 1720 patients (Griffin et al. 2007). Similarly, a post-hoc cost-effectiveness analysis conducted in Italy comparing standard treatment for CAD versus standard treatment plus amlodipine showed that savings were achieved with antianginal therapy because of a reduction in the need for revascularization (De Portu et al. 2006). As a consequence, ivabradine may play a role in the future by reducing the need for $\mathrm{PCl}$ in SAP patients, improving cost effectiveness of the treatment for SAP, but further population studies must be conducted to confirm this hypothesis.

In its more recent Guidelines for the Management of Angina Pectoris (ESC 2006), the European Society of Cardiology (ESC) has recommended the use of ivabradine as an alternative treatment for SAP if beta blockers are not tolerated or are contraindicated.

\section{Patient group/population}

Ivabradine shares with beta blockers the property of decreasing $\mathrm{HR}$ and oxygen demand from the ischemic heart, which is presumably fundamentally important in mediating antiischemic effects. In light of the positive results obtained in clinical trials, the place of ivabradine in the therapeutic armamentarium must be considered. Given the absence of cardiac effects other than exclusive HR lowering, ivabradine is probably suitable for most patients with SAP and is of particular interest in patients in whom beta blockers should be avoided (those with AV block, peripheral vascular disease, and obstructive pulmonary disease) and in those in whom tolerability of beta blockers or CCAs is an issue. Unlike beta blockers, ivabradine may be used in vasospastic angina because it does not increase coronary vasomotor tone.

In addition to depression, fatigue, and cold extremities, erectile dysfunction is a particularly important side effect associated with the use of beta blockers in middle-aged men. CCAs or ivabradine may therefore be very useful in such patients. While asthma or chronic obstructive pulmonary disease represent only relative contraindications to beta blockade, some patients clearly develop bronchospasm and wheezing with beta blockers, which requires dose reduction or abrupt withdrawal. Such patients who require $H R$ reduction would clearly benefit from the lack of this airways side effect with CCAs or ivabradine. Furthermore, some patients with both $\mathrm{CAD}$ and chronic obstructive pulmonary disease develop angina when treated with inhaled beta-adrenergic agonists because of the resulting tachycardia. The HR reduction obtained with ivabradine could also be very helpful in this setting.

Patients with CAD can have variable degrees of AV block that develop or are exacerbated with beta blockers. The need for selective HR reduction in patients with myocardial ischemia and mild AV node conduction abnormalities represents another indication for ivabradine. This is particularly relevant for older patients with a prolonged PR interval.

In summary, ivabradine can be used for the treatment of stable patients with CAD and angina who are intolerant of or have contraindications to beta blockers. It is also a logical addition for the treatment of angina when symptoms are not controlled by previous antianginal medications. 


\section{Dosage, administration, and formulations}

Ivabradine was approved in the EU by the European Medicines Agency on October 25, 2005, under the brand names Procoralan and Corlentor $^{\circledR}$ (Servier) (EMEA 2007). It is also available as the brand names Coralan ${ }^{\circledR}$ and Coraxan ${ }^{\circledR}$. As a pure HR-lowering agent, it is a unique medication from a new therapeutic class. It is available in 5 and $7.5 \mathrm{mg}$ film-coated tablets for oral administration. Its therapeutic indication is for symptomatic patients with chronic SAP and sinus rhythm who have a contraindication or intolerance to beta blockers. The starting dose should be $5 \mathrm{mg}$ twice daily, which may be titrated to $7.5 \mathrm{mg}$ twice daily if the response is not enough after 3 or 4 weeks of treatment. The drug should be taken once in the morning and once in the evening with meals. If the HR is persistently under $50 \mathrm{bpm}$ or if patients experience bradycardic symptoms like dizziness, hypotension, or fatigue, the dosage should be titrated downward to $2.5 \mathrm{mg}$ twice daily (half of a $5 \mathrm{mg}$ tablet). A lower starting dose should be considered for elderly patients, and ivabradine is not recommended for children or adolescents. Ivabradine should be used with caution if the creatinine clearance is below $15 \mathrm{~mL} / \mathrm{min}$ $(0.25 \mathrm{~mL} / \mathrm{s})$ since no safety data are available for this population of patients. It is presently contraindicated for patients with severe hepatic insufficiency, hypersensitivity, and in the presence of sinus bradycardia, cardiogenic shock, acute MI, severe hypotension, sick sinus syndrome, sinoatrial block, heart failure (New York Heart Association class III-IV), third degree AV block, a pacemaker, and unstable angina.

Ivabradine should not be combined with strong cytochrome P450 3A4 (CYP3A4) inhibitors. Concomitant use of ivabradine with nondihydropyridine CCAs such as verapamil or diltiazem is not recommended, but no safety issues have been raised regarding the combination with nitrates and dihydropyridine CCAs such as amlodipine. Ivabradine should also not be prescribed to pregnant and lactating women.

Stopping treatment should be considered, along with other possible causes such as retinal disease, if unexpected deterioration of visual function occurs, because the long-term retinal effects of ivabradine are not known. Nevertheless, a detailed ophthalmologic study of 300 patients has not revealed any structural eye abnormalities after 12 months of treatment with ivabradine (unpublished data). Close monitoring of patients with a prolonged QT interval is needed if the use of ivabradine cannot be avoided.

\section{Clinical value}

HR slowing is an integral part of an optimal pharmacologic antiischemic and antianginal strategy. Beta blockers have traditionally been considered as a first-line therapy for stable angina, but their use may be limited by side effects including fatigue, depression, and sexual dysfunction. Bronchospasm and AV block represent other limitations of beta blockers. Ivabradine is a selective and specific $I_{\mathrm{f}}$ inhibitor with antianginal and antiischemic effects that have been shown to be noninferior to those of the beta blocker atenolol and the CCA amlodipine. Unlike beta blockers, ivabradine is devoid of intrinsic negative inotropic effects and does not affect coronary vasomotion. A whole range of patients with angina may benefit from exclusive HR reduction with ivabradine, including those with contraindications or intolerance to the use of beta blockers and patients who are insufficiently controlled by beta blockers or CCAs.

The efficacy of combination therapy with ivabradine and atenolol is currently being assessed in a randomized, double-blind, placebo-controlled trial of 750 patients with documented SAP and $C A D$ and previous treatment with a beta blocker. The ability of ivabradine to decrease HR without depressing left ventricular function also makes it a potentially very interesting medication for the treatment of angina in patients with left ventricular dysfunction. The ongoing BEAUTIFUL (morBidity-mortality EvAlUaTion of the $I_{\mathrm{f}}$ inhibitor ivabradine in patients with coronary disease and left ventricULar dysfunction) study is assessing the effect of ivabradine on cardiovascular outcomes in patients with both CAD and left ventricular systolic dysfunction, and the results of this major clinical trial are expected in 2008 (Fox et al. 2006). Finally, the ongoing SHIFT (Systolic Heart failure treatment with the If inhibitor ivabradine Trial) is evaluating the potential role of ivabradine in reducing cardiovascular mortality and morbidity in patients with heart failure and at least moderate left ventricular systolic dysfunction (ISRCTN 2008).

\section{Acknowledgments}

Dr Tardif has received honoraria from Servier Laboratories. Guillaume Marquis-Gravel declares no conflict of interest.

\section{References}

AHA (American Heart Association). Heart disease and stroke statistics. 2008. Available at: http://www.americanheart.org/presenter.jhtml?identifier=3000090 (accessed February 2008).

Akhras F, Jackson G. Efficacy of nifedipine and isosorbide mononitrate in combination with atenolol in stable angina. Lancet. 1991;338:1036-1039.

Borer JS, Fox K, Jaillon P, Lerebours G; Ivabradine Investigators Group. Antianginal and antiischemic effects of ivabradine, an If inhibitor, in stable angina: a randomized, double-blind, multicentered, placebo-controlled trial. Circulation. 2003;107:817-823.

Brogden RN, Benfield P. Verapamil: a review of its pharmacological properties and therapeutic use in coronary artery disease. Drugs. 1996;51:792-819.

Campeau L. Letter: grading of angina pectoris. Circulation. 1976;54:522-523.

Cheitlin MD, Hutter AM Jr, Brindis R, et al. ACC/AHA expert consensus document. Use of sildenafil (Viagra) in patients with cardiovascular disease. American College of Cardiology/American Heart Association. J Am Coll Cardiol. 1999;34:1850.

Colin P, Ghaleh B, Monnet X, et al. Contributions of heart rate and contractility to myocardial oxygen balance during exercise. Am J Physiol Heart Circ Physiol. 2003;284:H676-H682.

Coumel P. Safety of bepridil: from review of the European data. Am J Cardiol. 1992;69:75D-78D.

Cucherat M. Quantitative relationship between resting heart rate reduction and magnitude of clinical benefits in post-myocardial infarction: a meta-regression of randomized clinical trials. Eur Heart J. 2007;28:3012-3019.

Deckers JW. Epidemiological review of stable angina. In: Fox K, Ferrari R, editors. Heart rate management in stable angina. Abingdon: Taylor \& Francis; 2005,pp.1-16.

Demontis GC, Moroni A, Gravante B, et al. Functional characterisation and subcellular localisation of HCN1 channels in rabbit retinal rod photoreceptors. J Physiol. 2002;542:89-97. 
De Portu S, Menditto E, Scalone L, Bustacchini S, Cricelli C, Mantovani LG. The pharmacoeconomic impact of amlodipine use on coronary artery disease. Pharmacol Res. 2006;54:158-163.

Diamond GA. A clinically relevant classification of chest discomfort. J Am Coll Cardiol. 1983;1:574-575.

Diaz A, Bourassa MG, Guertin MC, Tardif JC. Long-term prognostic value of resting heart rate in patients with suspected or proven coronary artery disease. Eur Heart J. 2005;26:967-974.

DiFrancesco D, Camm JA. Heart rate lowering by specific and selective $I_{f}$ current inhibition with ivabradine: a new therapeutic perspective in cardiovascular disease. Drugs. 2004;64:1757-1765.

Egstrup K. Transient myocardial ischemia after abrupt withdrawal of antianginal therapy in chronic stable angina. Am J Cardiol. 1988;61:1219-1222.

EMEA (European Medicines Agency). EPARs for authorised medicinal products for human use. 2007. Available at:

http://www.emea.europa.eu/humandocs/Humans/EPAR/procoralan/procoralan. htm (accessed August 2007).

ESC (European Society of Cardiology). The Task Force on the Management of stable angina pectoris of the European Society of Cardiology. Guidelines on the management of stable angina pectoris. 2006. Available at: http://www.escardio.org/NR/rdonlyres/16E8EA50-50AA-467E-B53EC55E83F05D8A/0/guidelines_Angina_FT_2006.pdf (accessed July 2007).

Estacio RO, Jeffers BW, Hiatt WR, Biggerstaff SL, Gifford N, Schrier RW. The effect of nisoldipine as compared with enalapril on cardiovascular outcomes in patients with non-insulin-dependent diabetes and hypertension. $N$ Engl $J$ Med. 1998;338:645-652.

Fox KM, Mulcahy D, Findlay I, Ford I, Dargie HJ. The Total Ischaemic Burden European Trial (TIBET). Effects of atenolol, nifedipine SR and their combination on the exercise test and the total ischaemic burden in 608 patients with stable angina. The TIBET Study Group. Eur Heart J. 1996;17:96-103.

Fox K, Ferrari R, Tendera M, Steg PG, Ford I; BEAUTIFUL Steering Committee. Rationale and design of a randomized, double-blind, placebo-controlled trial of ivabradine in patients with stable coronary artery disease and left ventricular systolic dysfunction: the morBidity-mortality EvAlUaTion of the I(f) inhibitor ivabradine in patients coronary disease and left ventricULar dysfunction (BEAUTIFUL) study. Am Heart J. 2006;152:860-866.

Frishman WH. Beta-adrenergic blocker withdrawal. Am J Cardiol. 1987;59:26F-32F.

Furberg CD, Psaty BM, Meyer JV. Nifedipine. Dose-related increase in mortality in patients with coronary heart disease. Circulation. 1995;92:1326-1331.

Gandhi MM, Lampe FC, Wood DA. Incidence, clinical characteristics, and short-term prognosis of angina pectoris. Br Heart J. 1995;73:193-198.

Gibbons RJ, Abrams J, Chatterjee K, et al; ACC/AHA Task Force on Stable Angina Guidelines. ACC/AHA 2002 guidelines update for the management of patients with chronic stable angina. Available at: http://www.acc.org/qualityandscience/clinical/guidelines/stable/stable_clean. pdf (accessed July 2007).

Griffin SC, Barber JA, Manca A, et al. Cost effectiveness of clinically appropriate decisions on alternative treatments for angina pectoris: prospective observational study. BMJ. 2007;334:624.

Guth BD, Heusch G, Seitelberger R, Ross J Jr. Mechanism of beneficial effect of beta-adrenergic blockade on exercise-induced myocardial ischemia in conscious dogs. Circ Res. 1987;60:738-746.

Hanania G, Cambou JP, Guéret P, et al; USIC 2000 Investigators. Management and in-hospital outcome of patients with acute myocardial infarction admitted to intensive care units at the turn of the century: results from the French nationwide USIC 2000 registry. Heart. 2004;90:1404-1410.

Heidenreich PA, McDonald KM, Hastie T, et al. Meta-analysis of trials comparing beta-blockers, calcium antagonists, and nitrates for stable angina. JAMA. 1999;281:1927-1936.

Heidland UE, Strauer BE. Left ventricular muscle mass and elevated heart rate are associated with coronary plaque disruption. Circulation.

2001;104:1477-1482.
ISRCTN (International Standard Randomised Controlled Trial Number). Effects of ivabradine on cardiovascular events in patients with moderate to severe chronic heart failure and left ventricular systolic dysfunction. A three-year randomised double-blind placebo-controlled international multicentre study. 2008. Available at: http://www.controlled-

trials.com/ISRCTN70429960/ivabradine (accessed February 2008).

Kannel WB, Hjortland MC, McNamara PM, Gordon T. Menopause and risk of cardiovascular disease: the Framingham study. Ann Intern Med. 1976;85:447-452.

Kannel WB, Kannel C, Paffenbarger RS Jr, Cupples LA. Heart rate and cardiovascular mortality: the Framingham Study. Am Heart J. 1987;113:1489-1494.

Ko DT, Hebert PR, Coffey CS, Sedrakyan A, Curtis JP, Krumholz HM. Betablocker therapy and symptoms of depression, fatigue, and sexual dysfunction. JAMA. 2002;288:351-357.

Lacoste LL, Théroux P, Lidón RM, Colucci R, Lam JY. Antithrombotic properties of transdermal nitroglycerin in stable angina pectoris. Am J Cardiol. 1994;73:1058-1062.

Manz M, Reuter M, Lauck G, Omran H, Jung W. A single intravenous dose of ivabradine, a novel I(f) inhibitor, lowers heart rate but does not depress left ventricular function in patients with left ventricular dysfunction. Cardiology. 2003;100:149-155.

Mensink GB, Hoffmeister $\mathrm{H}$. The relationship between resting heart rate and allcause, cardiovascular and cancer mortality. Eur Heart J. 1997;18:1404-1410.

Newby LK, LaPointe NM, Chen AY, et al. Long-term adherence to evidencebased secondary prevention therapies in coronary artery disease. Circulation. 2006;113:203-212.

Pepine CJ. Angina pectoris in a contemporary population: characteristics and therapeutic implications. TIDES Investigators. Cardiovasc Drugs Ther. 1998;12 (Suppl. 3):211-216.

Perski A, Olsson G, Landou C, de Faire U, Theorell T, Hamsten A. Minimum heart rate and coronary atherosclerosis: independent relations to global severity and rate of progression of angiographic lesions in men with myocardial infarction at a young age. Am Heart J. 1992;123:609-616.

Rehnqvist N, Hjemdahl P, Billing E, et al. Effects of metoprolol vs verapamil in patients with stable angina pectoris: The Angina Prognosis Study in Stockholm (APSIS). Eur Heart J. 1996;17:76-81.

Ruzyllo W, Tendera M, Ford I, Fox KM. Antianginal efficacy and safety of ivabradine compared with amlodipine in patients with stable effort angina pectoris: a 3-month randomised, double-blind, multicentre, noninferiority trial. Drugs. 2007;67:393-405.

Saha M, Marber MS. If at first you don't succeed try.... new target in the treatment of angina. Eur Heart J. 2005;26:2482-2483.

Savelieva I, Camm JA. Novel If current inhibitor ivabradine: safety considerations. In: Camm J, Tendera M, editors. Heart rate slowing by If current inhibition. Basel: Karger; 2006, pp. 79-96 (Advances in Cardiology, vol 43).

Shaw LJ, Merz CN, Pepine CJ, et al; Women's Ischemia Syndrome Evaluation (WISE) Investigators. The economic burden of angina in women with suspected ischemic heart disease: results from the National Institutes of Health-National Heart, Lung, and Blood Institute-sponsored Women's Ischemia Syndrome Evaluation. Circulation. 2006;114:894-904.

Simon L, Ghaleh B, Puybasset L, Giudicelli JF, Berdeaux A. Coronary hemodynamic effects of S16257, a new bradycardic agent, in resting and exercising conscious dogs. J Pharmacol Exp Ther. 1995;275:659-666.

Singh BN. Safety profile of bepridil determined from clinical trials in chronic stable angina in the United States. Am J Cardiol. 1992;69:68D-74D.

Singh BN. Morbidity and mortality in cardiovascular disorders: impact of reduced heart rate. J Cardiovasc Pharmacol Therapeut. 2001;6:313-331.

Tafreshi MJ, Weinacher AB. Beta-adrenergic-blocking agents in bronchospastic diseases: a therapeutic dilemma. Pharmacotherapy. 1999;19:974-978.

Tardif JC, Ford I, Tendera M, Bourassa MG, Fox K; INITIATIVE Investigators. Efficacy of ivabradine, a new selective $I(f)$ inhibitor, compared with atenolol in patients with chronic stable angina. Eur Heart J. 2005;26:2529-2536.

Tendera M. If inhibition: from pure heart rate reduction to treatment of stable angina. Eur Heart J Suppl. 2005;7(Suppl. H):H3-H6. 
Ivabradine | clinical impact review

Tendera M, Fox K, Tardif JC, Ford I. Anti-ischemic and antianginal efficacy of ivabradine, a selective and specific If current inhibitor, in elderly patients with stable angina. Circulation. 2006;114(Suppl. II):715. (Abstract)

Thadani U, Rodgers T. Side effects of using nitrates to treat angina. Expert Opin Drug Saf. 2006;5:667-674.

Wallace WA, Wellington KL, Chess MA, Liang CS. Comparison of nifedipine gastrointestinal therapeutic system and atenolol on antianginal efficacies and exercise hemodynamic responses in stable angina pectoris. Am J Cardiol. 1994;73:23-28.
Zaza A, Rocchetti M. Regulation of the sinoatrial pacemaker: selective If inhibition by ivabradine. In: Fox K, Ferrari R, editors. Heart rate management in stable angina. Abingdon: Taylor \& Francis; 2005, pp. 51-67.

Correspondence: Jean-Claude Tardif, MD, Research Center, Montreal Heart Institute, 5000 Belanger Street, Montreal, Quebec, Canada H1T 1C8 or at jean-claude.tardif@icm-mhi.org 